\title{
Model to enhance knowledge sharing process in academia during COVID-19
}

\author{
Zainab Amin Alsulami ${ }^{1}$, Hayder Salah Hashim², Zaid Ameen Abduljabbar ${ }^{3}$ \\ ${ }^{1}$ College of sciences, University of Basrah, Basrah, Iraq \\ ${ }^{2}$ College of Administration and Economics, University of Basrah Basrah, Basrah, Iraq \\ ${ }^{3}$ College of Education for Pure Sciences, University of Basrah, Basrah, Iraq
}

\begin{tabular}{l} 
Article Info \\
\hline Article history: \\
Received Jun 27, 2021 \\
Revised Aug 10, 2021 \\
Accepted Jan 5, 2022 \\
\hline Keywords: \\
Higher education institutions \\
Knowledge management \\
knowledge-sharing process \\
TOE model \\
Web 2.0 technologies
\end{tabular}

\begin{abstract}
Knowledge sharing (KS) is considered one of the essential processes of knowledge management (KM). Recently, the emerging Web 2.0 technologies were used by academicians and students for KS during the COVID-19 pandemic. The purpose of this study is to identify the factors that affect the knowledge-sharing process through Web 2.0 (KSWT 2.0) technologies and their impact on academic performance within higher educational institutions (HEIs) in Iraq. The technology-organizationenvironment (TOE) theory was used in this study to develop the conceptual framework. The population includes students and academicians at Basrah University in Iraq. Using stratified random sampling, a total of 415 academicians and students participated in this study. The results revealed that the most significant factors that positively affect KSWT 2.0 technologies were the technological factor such as relative advantage, compatibility. From the organisational factor academicians' skills and knowledge, and from environmental factor, the peer pressure. In addition, the results proved that the KSWT 2.0 technologies positively maximised academic performance. The results presented in this study are valuable for Iraqi universities that implement or aim to use Web 2.0 technologies in the knowledge-sharing process.
\end{abstract}

This is an open access article under the CC BY-SA license.

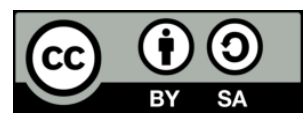

\section{Corresponding Author:}

Zainab Amin Alsulami

College of sciences, University of Basrah, Basrah, Iraq

Email: Zainab.abduljabba@uobasrah.edu.iq

\section{INTRODUCTION}

Knowledge is considered the most important organizational asset. Managing knowledge is one of the important tasks for organization [1]. In managing knowledge, there are five important steps that must be considered. These include acquiring, collecting, storing, reusing, retrieval, sharing, and refining the knowledge. Hence, these processes formulated the KM life cycle [2]. Knowledge sharing (KS) is one of the essential processes in the KM life cycle. It is the process of exchanging thoughts, experiences, expertise, and solutions concurred by the giver and receiver [3]. In general, knowledge can be shared via face-to-face communications in a real-time environment which consumes time and effort. In the age of corona virus disease (COVID-19), knowledge is shared electronically in various soft-copy formats such as documents, pictures, videos, and sound recordings. This electronic-sharing process is performed through online applications, such as Web 2.0 technologies which disseminate knowledge in a virtual environment.

During the recent COVID-19 pandemic, it was crucial to adopt these Web 2.0 applications to communicate and collaborate between academicians and students in universities worldwide [3]. The learning processes have changed to distance learning, and this unexpected transformation instigated universities to 
utilise Web 2.0 online applications for knowledge-sharing activities [4]. Traditionally, a formal learning management system is used in universities for the learning process. However, this kind of system is absent in Iraq due to weak information technology (IT) infrastructure [5]. For that reason, academicians and students relied entirely on Web 2.0 online applications to share their knowledge.

The knowledge sharing through Web 2.0 (KSTW 2.0) technologies is impacted by several factors that could enhance knowledge dissemination between academicians and their students. Besides, it could be observed that successful KS enhances the learning process [6]. The learning process also increases academicians' performance in a way that enriches students' minds with understandable and absorbable knowledge during the COVID-19 lockdown. The TOE model was used in this study to identify the efficient factors that affect the knowledge-sharing process via Web 2.0 technologies. Previous studies discovered that the TOE model is suitable for analysing and implementing certain technologies [7]-[9]. Furthermore, numerous researchers have employed the TOE model to adopt internet technologies [10]-[12]. Hence, it was decided that the TOE model is suitable to use in this research. Nevertheless, using this model in the knowledge-sharing process at higher education institutions (HEIs) is still limited [2], [13], [14].

Further, few studies have specifically implemented the TOE model to analyse the factors that affect the knowledge-sharing process through Web 2.0 technologies among academicians and students in universities. Most past studies used this model to investigate the effect of factors that influence KS in business enterprises such as small and medium-sized enterprises (SMEs). Thus, this is among the first study that identified the factors affecting the KSWT 2.0 technologies, specifically among academicians and students in Iraqi HEIs. This study includes seven sections: introduction, interpretation of related works, the hypotheses and the research model and the proposed factors, methodology, findings, results and discussion, conclusion, limitations, and future work directions were suggested.

\section{LITERATURE REVIEW}

\subsection{Knowledge management in HEI}

KM enhances the overall performance of many organisations to increase their competitive advantages [15]. Massa and Testa [16] defined KM as the aggregation of technology, people, and processes working together to create knowledge that enhances the organisation's performance. KS is an essential process of KM [2], [17]. In principle, knowledge-sharing techniques and activities are applied to maximise an organisation's profits [18]. Similarly, HEIs should apply knowledge-sharing techniques and activities to enhance their teaching and academic performance since universities are considered knowledge-based organisations. Academicians are the knowledge workers who disseminate their knowledge as syllabus, lectures, solutions, and research. Academicians should practice three main activities throughout their career: teaching, supervision, and researching [19] to distribute knowledge continuously. Numerous methods are applied to share knowledge in universities traditionally, such as KS through face-to-face communications between academicians and their students. In fact, real communication is deemed the most powerful method to share knowledge successfully. Nevertheless, the COVID-19 pandemic demanded an urgent need to convert face-to-face communication with online distance communication techniques [16].

\subsection{Web 2.0 technologies as educational platform for $\mathrm{KS}$}

Web 2.0 technologies are defined as electronic platforms to interact with content, disseminate it from different sources, retrieve the content, and aggregate it to reach various sources [20]. Web 2.0 technologies comprise various online applications. Practically, Web 2.0 technologies allow users to collaborate, interact, and gain knowledge by retrieving and sharing different knowledge formats such as texts, documents, videos, audios, and graphics. Therefore, Web 2.0 technologies enable people worldwide to share their knowledge efficiently [21]. The rapid growth of Web 2.0 technologies has compelled HEIs to implement it as a supporting technology to communicate and collaborate globally [6]. Essentially, universities in Iraq use Web 2.0 technologies as a medium to collaborate and communicate with academicians and students. Nonetheless, this practice is still weak due to the existence of actual face-to-face communications. During the COVID-19 outbreak, universities immediately adopted Web 2.0 technologies to distribute the required knowledge among academicians and students due to the absence of real communication [5]. Additionally, the absence of a formal information management system increased the fast adoption of this technology [22].

\subsection{The TOE model}

Drazin [23] developed the TOE, and it consists of three aspects: technological aspect, organisational aspect, and environmental aspect. The technological aspect describes specific features of the chosen technology, and the organisational aspect is the specific attributes of the organisation that adopted the chosen technology, while the environmental aspect is the nature of the environment wherein the organisation that 
adopted the chosen technology works [23]. Previous studies employed the TOE model as a useful theoretical model to test the implementation and the use of numerous technologies such as cloud computing, electronic governance (e-governance), electronic commerce (e-commerce), and various information support systems (ISS) [7], [9], [24]. Recently, the TOE model was utilised to investigate the implementation and the use of internet technologies such as Web 2.0 technologies [10]-[12]. Therefore, this study selected this model since it is suitable to test the factors that influence KSTW 2.0.

\section{RESEARCH MODEL AND HYPOTHESES}

The sections below discussed the technological aspect, organisational aspect, and environmental aspect as well as the selected factors in the model of this study.

\subsection{Technological aspect}

The technological aspect includes internal and external technology that the organisation should implement to enhance their performance [25]. Thus, the usage of Web 2.0 technologies depends on several factors that affect the knowledge-sharing process and the level of enhancement that could increase the academicians' performance. The factors that affect KSTW 2.0 technologies are discussed below.

\subsubsection{Relative advantage}

Relative advantage is defined as an essential factor that directly affects the implementation of certain technologies [26]. Furthermore, this factor represents the new benefits and advantages of the utilised chosen technology [27]. In this study, Web 2.0 technologies offer new benefits and advantages to academicians and students in HEIs. Consequently, the following hypothesis is proposed:

H1: Relative advantage has a positive impact on the knowledge-sharing process through Web 2.0 technologies

\subsubsection{Compatibility}

Compatibility is defined as the factor that ensures the chosen technology is compatible with the working environment's internal culture [28]. It should be noted that employees' perception of the chosen technology indicates that it is aligned with the organisation's values, assets, and potential needs [29]. Besides, [12] reported that compatibility is a significant factor influencing the adoption and utilisation of Web 2.0 technologies (such as social media) in business companies or SMEs. In this current study, Web 2.0 technologies offer harmonious technology to academicians and students in HEIs to share their knowledge effectively. Therefore, the following hypothesis is proposed:

H2: Compatibility has a positive impact on the knowledge-sharing process through Web 2.0 technologies

\subsubsection{Complexity}

If the chosen technology is easy to understand and implement, then it will be adopted [28]. Notably, [11] stated that complexity negatively affects the adoption of the KM system used to share knowledge in business organisations. In the context of this study, Web 2.0 technologies are perceived as a complicated technology among academicians in HEIs in terms of KS. Hence, the following hypothesis is submitted:

H3: Complexity has a negative impact on the knowledge-sharing process through Web 2.0 technologies

\subsubsection{Information technology integration}

Web 2.0 technologies used for KS depend on an organisation's technological capabilities [10]. IT integration facilitates communication and cooperation, which enhances the knowledge-sharing process. Nevertheless, [10] stated that the results proved that IT integration is not an important factor with no positive impact on Web 2.0 technologies usage in SMEs due to the availability of highly advanced IT infrastructures. In this present study, Web 2.0 technologies were adopted successfully due to the availability of IT recourses (IT integration) for academicians and students in HEIs to share their knowledge. Consequently, the following hypothesis is proposed:

H4: IT integration has a positive impact on the KSWT 2.0 technologies

\subsubsection{IT expertise}

Soto-Acosta et al. [10] explained that IT expertise is an essential technological issue to successfully adopt Web 2.0 technologies for KS in business organisations. Web 2.0 technologies were successfully adopted in this current study with the availability of IT professionals (IT expertise) among academicians and students in HEIs during KS. Hence, the following hypothesis is proposed:

H5: IT expertise has a positive impact on the KSWT 2.0 technologies. 


\subsection{Organisational aspect}

The organisational aspect involves the characteristics and resources of an organisation that adopts and implements certain technologies such as internal processes, willingness to learn, top management support, and linkages among employees [25]. In this study, KS occurred when the organisation's employees are willing to share their knowledge and expertise. Additionally, it is crucial for employees to have full support from the top management that encourages them to share knowledge effectively. In terms of the organisational aspect, the factors that could affect KSTW 2.0 were identified and discussed below.

\subsubsection{Academicians' skills and knowledge}

Academicians and students who acquire high-level technical skills efficiently utilised Web 2.0 technologies to share the required knowledge [12]. Ndaba et al. [11] submitted that there is a positive relationship between the employee's KM system and its adoption in a company. This study presented that Web 2.0 technologies can be adopted successfully by academicians and students in HEIs during KS if they have a high knowledge level and skills of the same technologies. Thus, the following hypothesis is posited: H6: Academicians' skills and knowledge has a positive impact on the KSWT 2.0 technologies

\subsubsection{Top management support}

Top management support is the willingness and positive attitude of decision-makers and stakeholders to provide all the possible financial support and other tangible resources in adopting and implementing the chosen technology [30]. Furthermore,[12] stated that top management support could affect social media usage and determine the success of the practical implementations. In contrast, [11] revealed that top management support has no significant impact on KM processes, such as KS. In this current research, the university's president and dean's panel could support the knowledge-sharing process among the academicians and students by providing them with financial and logistical support to successfully adopt and implement Web 2.0 technologies. Thus, the following hypothesis is presented:

H7: Top management support has a positive impact on the KSWT 2.0 technologies

\subsubsection{Commitment-based HR practices}

Commitment-based human resource (HR) practices are defined as the organisational human resource practices that build a strong commitment between employees, thus motivating them to share their knowledge [31]. Acosta et al. [10] proved that commitment-based HR practices have a positive relationship with Web 2.0 technologies usage for KS in business organisations. In this study, commitment-based HR practices provide an active climate that could trigger the collaboration among academicians to work together and share the required knowledge using Web 2.0 technologies. Hence, the following hypothesis is forwarded: H8: Commitment-based HR practices have a positive impact on the KSWT 2.0 technologies

\subsubsection{Rewards}

A reward is defined as the progression of encouraging employees to fulfil certain goals set by an organisation [32]. Farooq [18] demonstrated that rewards positively affect the knowledge-sharing process through the chosen information system platform. On another note, [7] discovered that if organisational rewards increase the knowledge-sharing process among academic staff at HEIs increases positively. Rewards formulated as bonuses are considered the most suitable form to promote KS for academic staff. In this study's context, university management should encourage the KSWT 2.0 technologies by providing rewards or bonuses for academicians who continuously share their knowledge. Therefore, the following hypothesis is posited:

H9: Rewards has a positive impact on the KSWT 2.0 technologies

\subsubsection{Culture}

Culture could enhance the knowledge-sharing process if it encourages the employees to disseminate their knowledge as individuals or groups [33]. Farooq [18] stated that organisational culture deeply affects the knowledge-sharing process. Meanwhile, [10] expressed that culture should be studied in future research since it is a crucial organisational factor that could positively enrich KSTW 2.0. In this study, university management should utilise a positive culture that encourages academicians to share their knowledge spontaneously, not as forced actions and attitudes. This culture could be instilled in the long term by increasing academicians' willingness to disseminate their knowledge using Web 2.0 technologies as a modern method for KS. Based on this aspect, the following hypothesis is proposed:

H10: Culture has a positive impact on the KSWT 2.0 technologies 


\subsection{Environmental aspect}

The environmental aspect is the external factors affecting the implementation and adoption of certain technologies or innovations such as competitors, suppliers, partners, and government support and regulations [34]. Moreover, this aspect represents the external environment of a specific organisation. This study presented that the adoption of Web 2.0 technologies to disseminate academicians' knowledge is influenced by external factors such as peer pressure, government support, and stakeholders' pressure. Although the previous technological and organisational aspects are significant, the environmental aspect could encourage or hinder organisations from adopting certain technologies [12]. Thus, environmental factors could negatively or positively influence the KSWT 2.0 [10]. Referring to this aspect, the factors that could affect KSTW 2.0 technologies are identified and discussed below.

\subsubsection{Government support}

Government positively affects the adoption of certain technologies in organisations by providing financial assistance, assets, and IT infrastructures [12], [35]. In contrast, if the government cuts off monetary assistance and legislate centralised technology for all organisations, they could hinder the technology usage chosen by the organisation [12]. On the other hand, [36] argued that government support and regulations neutrally affect the utilisation of cloud computing technology. In this current research, the government positively supports academicians and students to adopt Web 2.0 technologies as a platform for knowledge sharing by providing financial support to cover the payment of application accounts, IT devices, and the required infrastructures. Hence, the following hypothesis is posited:

H11: Government support has a positive impact on the KSWT 2.0 technologies

\subsubsection{Peer pressure}

Findings in regard to peer pressure is mixed. Peer pressure has no significant impact on cloud computing usage in universities [36]. In addition, [11] stated that there is no relationship between the pressure of employees in the same industry, albeit in different organisations, and the adoption of the same KM system. In contrast, this paper presented that academicians and university top management tend to imitate their colleagues in other universities, i.e., those who adopt Web 2.0 technologies as a modern method to share knowledge. Therefore, the following hypothesis is presented:

H12: Peer pressure has a positive impact on the KSWT 2.0 technologies

\subsection{KSTW 2.0 technologies and academic performance}

Knowledge is defined as a combination of employee's insights, ideas, experiences, and problem solutions that could enhance the organisation's competitive advantage and overall performance [15]. Obeidat and Tarhini [33] discovered that knowledge-sharing practices and mechanisms could positively affect an employee's job performance. Furthermore, [17] submitted that efficient KM processes in universities such as KS could increase an academician's performance in their working environment. Besides, a basic activity such as teaching, researching, and supervision could be enhanced when there is an efficient KSWT 2.0 technologies are one of the most successful online technologies used to disseminate knowledge by providing a virtual space where academicians can share knowledge and information in real time [19]. Moreover, this technology facilitates the arrangement of virtual classes between lecturers and students to virtualise the actual learning and teaching process from remote places [6], [37]. Hence, using Web 2.0 technologies for KS can positively affect an academician's performance. Consequently, the following hypothesis is proposed:

H13: KSTW 2.0 technologies have a positive impact on academic performance

\section{RESEARCH METHODOLOGY}

This study focuses on Basrah University in Iraq due to its large population. The university has 22 colleges and 21 centres offering various programmes. According to the university website, there are 93,437 students and 5,398 academic staff [38]. Since these three groups are different with different characteristics, stratified sampling was used. A randomly selected sampling technique was used in each group. With reference to [39], the sample size in this study is 415 respondents. The data in this study is collected using a questionnaire. The questionnaire is adopted from previous studies. Measurement of relative advantage (5 items), compatibility (6 items), complexity (6 items), Academicians' skills and knowledge (7 items), and top management support (6 items) were adopted from [11] and [12]. IT integration (5 items), and IT expertise (4 items), Commitment (5 items), and culture (5 items) were adopted from [10]. Rewards (4 items) was adopted from [7] and ([18]). Government support (7 items) was adopted from [12], [36] peer pressure support (5 items) was adopted from [36] and [11] KSTW 2.0 (5 items) and academic performance (6 items) were adopted from [6] and [19]. 
The questionnaire was translated into Arabic and validated by three experts. A pilot study was conducted to assess its reliability and all the variables have a Cronbach's Alpha greater than 0.70 indicating that they are reliable [40]. The field data collection was conducted by sending emails to students and academic staff. This has resulted in 422 responses. Missing values analysis as well as outliers was conducted. This has resulted in removing seven responses due to outliers' issues. The data is normally distributed because the value of skewness and kurtosis is less than absolute 2 and there is no multicollinearity issue because the variance inflation factor (VIF) is less than 10 and the tolerance is greater than 0.10 as recommended by [41].

\section{FINDINGS}

\subsection{Demographics of respondents}

In total, 415 respondents have participated voluntarily in this study, mainly between the age of 19to 29 years $(240$ or $58 \%)$. The respondents comprised $267(64.3 \%)$ males and $148(35.7 \%)$ females. Most respondents were students (349 or $79.3 \%$ ) with a bachelor's degree (305 or $73.6 \%$ ). It should be noted that $378(91.1 \%)$ respondents have accessed Web 2.0 applications once a day.

\subsection{Hypotheses testing}

This study used SPSS version 25.0 for data analysis. The result of hypotheses testing is illustrated in Table 1. The three aspects explained $39.8 \%$ of the variation in KS towards increased academic performance, while KSTW 2.0 technologies explain $65.6 \%$ of the variation in academic performance.

Table 1. Coefficient of regression analysis

\begin{tabular}{|c|c|c|c|c|c|c|}
\hline & \multirow{2}{*}{ Model } & & \multicolumn{2}{|c|}{ Unstandardised coefficients } & \multirow{2}{*}{$\mathrm{T}$} & \multirow{2}{*}{ Sig. } \\
\hline & & & $\mathrm{B}$ & Std. error & & \\
\hline \multirow{14}{*}{ KSTW 2.0 technologies } & \multirow[t]{6}{*}{ Technological aspect } & (Constant) & 0.407 & 0.237 & 1.417 & 0.132 \\
\hline & & RA & 0.238 & 0.090 & 2.634 & 0.009 \\
\hline & & $\mathrm{C}$ & 0.186 & 0.083 & 2.248 & 0.005 \\
\hline & & $\mathrm{CX}$ & 0.101 & 0.054 & 3.019 & 0.061 \\
\hline & & IT IN & 0.124 & 0.023 & 5.104 & 0.042 \\
\hline & & IT EX & 0.123 & 0.026 & 2.913 & 0.044 \\
\hline & \multirow[t]{6}{*}{ Organisational aspect } & (Constant) & -0.217 & 0.213 & -1.042 & 0.203 \\
\hline & & ASK & 0.229 & 0.058 & 3.008 & 0.008 \\
\hline & & TMS & 0.108 & 0.075 & 2.249 & 0.035 \\
\hline & & $\mathrm{CB}$ & 0.119 & 0.053 & 3.003 & 0.023 \\
\hline & & $\mathrm{RE}$ & 0.120 & 0.022 & 5.105 & 0.040 \\
\hline & & $\mathrm{CU}$ & 0.113 & 0.022 & 2.913 & 0.004 \\
\hline & \multirow[t]{3}{*}{ Environmental aspect } & (Constant) & 0.476 & 0.336 & 1.495 & 0.122 \\
\hline & & GS & 0.108 & 0.084 & 2.250 & 0.045 \\
\hline \multirow{3}{*}{\multicolumn{2}{|c|}{ Academic performance }} & PP & 0.229 & 0.059 & 3.009 & 0.009 \\
\hline & & (Constant) & -0.129 & 0.210 & -1.031 & 0.102 \\
\hline & & KSW 2.0 & 0.794 & 0.037 & 24.300 & 0.007 \\
\hline
\end{tabular}

The result of hypothesis testing showed that the effect of relative advantage on the KSTW 2.0 technologies was significant $(\mathrm{B}=0.238$, P-value $<0.05)$. Thus, $\mathrm{H} 1$ is accepted. The second hypothesis on compatibility in the KSTW 2.0 technologies was also significant $(\mathrm{B}=0.186$, P-value $<0.05)$. Thus, H2 is accepted. However, complexity was $(\mathrm{B}=0.101$, P-value $<0.61)$, indicating that $\mathrm{H} 3$ is not accepted. Other factors of the TOE technological aspect such as IT integration $(B=0.124, \mathrm{P}$-value $<0.05)$, and IT expertise $(\mathrm{B}=0.123$, P-value $<0.05)$ were significant. Thus, H4 and H5 are accepted. Academicians' skills and knowledge impact on the KSWT 2.0 technologies were significant $(\mathrm{B}=0.229$, P-value $<0.05)$. Thus, H6 is accepted. Similarly, the effect of top management support had a significant impact on the KSWT 2.0 technologies to increase academic performance $(\mathrm{B}=0.108, \mathrm{P}$-value $<0.05)$. Hence, $\mathrm{H} 7$ is accepted. Equally, other TOE organisational aspects such as commitment-based HR practices, rewards, and culture were significant. Thus, H8, H9, and $\mathrm{H} 10$ are accepted. In addition, peer pressure was proposed as a determinant of the KSWT 2.0 technologies. The findings revealed that peer pressure is a strong factor affecting the KSWT 2.0 technologies to increase academic performance $(\mathrm{B}=0.229$, P-value $<0.05)$. Thus, H12 is accepted. Similarly, the effect of government support had less impact on the KSWT 2.0 technologies $(B=0.108$, P-value <0.05). Thus, H11 is accepted. The findings showed that the KSWT 2.0 technologies was a strong factor that affects academic performance $(\mathrm{B}=0.794$, $\mathrm{P}$-value $<0.05)$. Thus, $\mathrm{H} 13$ is accepted. 


\section{DISCUSSION AND IMPLICATIONS}

This study investigated 13 hypotheses using regression analysis to discover the impact of 12 TOE factors on the KSWT 2.0 technologies and its effect on the academic performance in Iraqi HEIs. The findings showed that among the technological aspect, the relative advantage was the most effective factor positively related to the KSWT 2.0 technologies. Followed by compatibility, IT integration and while complexity has insignificant effect. These findings are in line with the findings of previous work [10]-[12]. Hence, Basrah University should increase its benefits and advantages of sharing academician's knowledge successfully using Web 2.0 technologies. Regarding the organisational aspect, academicians' skills and knowledge followed by top management support, commitment, and culture were the most important factor that positively impacts the KSWT 2.0 technologies. These findings are in line with the findings of previous studies [10], [18]. Decision makers have to enhance the knowledge and skill, commitment, rewards, and culture to enhance the KS. Most significantly, Basrah University users considered government support an unimportant factor and relied more on internal management support to grant financial assistance, assets, and IT infrastructures. Peer pressure was also an influential factor that positively impacts the KSWT 2.0 technologies at Basrah University. Furthermore, the study proved a positive relationship between KSWT 2.0 technologies and academic performance. Identical results were also found in [10] who confirmed that the KSWT 2.0 technologies could develop user's innovation.

\section{CONCLUSION, LIMITATIONS, AND FUTURE WORK}

This study is based on the TOE model, which aimed to identify the factors that could affect the KSWT 2.0 technologies as IT platforms for KS and its effect on academic performance in Iraqi universities. The respondents in this study consisted of 415 participants who were academicians and students, and the data were analysed using SPSS version 25.0. The results suggested that TOE factors, namely relative advantages, compatibility, academicians' skills and knowledge, and peer pressure, are the most critical factors that impact the KSWT 2.0 technologies. On the other hand, the opposite was found concerning the technological factor (complexity). In addition, the results indicated that the KSWT 2.0 technologies maximised the academic performance level and value. This research has several limitations which should be addressed in future studies. Firstly, the sampling was obtained from Basrah University only, hence future studies should generalise this research by combining more than one university to collect the sample and present a more general perspective from Iraqi universities. Secondly, this research used a quantitative approach, thus future studies should use the qualitative approach such as interviews to confirm the findings of this research using different data collection methods. Finally, no previous studies have used the TOE model to investigate KSWT 2.0 technologies in universities. Therefore, future studies should analyse the factors that could affect the knowledge-sharing process using the TOE model in HEIs. In conclusion, future studies should consider these recommendations to enhance the innovations in KS and IT technologies used to implement this process as one of the most crucial KM processes.

\section{REFERENCES}

[1] R. Grant, "Toward a knoweldge-based theory of the firm," Strategic Management Journal., vol. 17, no. S2, pp. 109-122, 1996, doi: $10.1002 / \mathrm{smj} .4250171110$.

[2] F. Albream and M. Maraqa, "The impact of adopting e-collaboration tools on knowledge management processes," Management Science Letters, vol. 9, no. 7, pp. 1009-1028, 2019, doi: 10.5267/j.ms1.2019.4.004.

[3] V. D. Phung, I. Hawryszkiewycz, D. Chandran, and B. M. Ha, "Promoting knowledge sharing amongst academics: A case study from Vietnam," Journal of Information \& Knowledge Management, vol. 18, no. 03, p. 1950032, 2019.

[4] O. B. Adedoyin and E. Soykan, "Covid-19 pandemic and online learning: the challenges and opportunities," Interactive Learning Environments, Taylor \& Francis, pp. 1-13, 2020, doi: 10.1080/10494820.2020.1813180.

[5] N. Doghonadze, A. Aliyev, H. Halawachy, L. Knodel, and A. S. Adedoyin, "The Degree of Readiness to Total Distance Learning in the Face of COVID-19 - Teachers' View (Case of Azerbaijan, Georgia, Iraq, Nigeria, UK and Ukraine)," Journal of Education in Black Sea Region, vol. 5, no. 2, pp. 2-41, 2020, doi: 10.31578/jebs.v5i2.197.

[6] N. A. N. Amin, M. N. Almunawar, A. S. Hasnan, and N. N. Besar, "The utilization of Web 2.0 for knowledge sharing: The case of tertiary education in Brunei Darussalam," in Handbook of Research on Managerial Practices and Disruptive Innovation in Asia, IGI Global, 2019, pp. 1-25.

[7] C. N.-L. Tan, "Enhancing knowledge sharing and research collaboration among academics: the role of knowledge management," Higher education, vol. 71, no. 4, pp. 525-556, 2016.

[8] H. O. Awa, O. Ukoha, and S. R. Igwe, "Revisiting technology-organization-environment (TOE) theory for enriched applicability," Bottom Line, 2017.

[9] R. El-Haddadeh, "Digital Innovation Dynamics Influence on Organisational Adoption: The Case of Cloud Computing Services," Information Systems Frontiers, vol. 22, no. 4, pp. 985-999, 2020, doi: 10.1007/s10796-019-09912-2.

[10] P. Soto-Acosta, D. Perez-Gonzalez, and S. Popa, "Determinants of Web 2.0 technologies for knowledge sharing in SMEs," Service Business, vol. 8, no. 3, pp. 425-438, 2014, doi: 10.1007/s11628-014-0247-9.

[11] S. L. Ndaba, "Adoption of knowledge management systems by South African municipalities: a technology-organizationalenvironment (TOE) perspective," Doctoral dissertation, Faculty of Commerce, Law and Management, University of the 
Witwatersrand, 2018.

[12] M. I. Effendi, D. Sugandini, and Y. Istanto, "Social Media Adoption in SMEs Impacted by COVID-19: The TOE Model," The Journal of Asian Finance, Economics and Business, vol. 7, no. 11, pp. 915-925, 2020, doi: 10.13106/jafeb.2020.vol7.no11.915.

[13] M. N. Muda and Z. M. Yusof, "Conceptual Framework for Knowledge Sharing Initiative in Institution of Higher Learning: The Establishment of Knowledge Repository,” Proceeding Knowledge Management International Conference 2014, Vols 12 , vol. 2, no. 2356, pp. 663-669, 2014.

[14] Y. D. L. Widyasari, L. E. Nugroho, and A. E. Permanasari, "Persuasive technology for enhanced learning behavior in higher education," International Journal of Educational Technology in Higher Education, vol. 16, no. 1, pp. 1-16, 2019.

[15] M. Alavi and D. E. Leidner, "Review: Knowledge management and knowledge management systems: Conceptual foundations and research issues," MIS Quarterly Management Information System, vol. 25, no. 1, pp. 107-136, 2001, doi: 10.2307/3250961.

[16] S. Massa and S. Testa, "A knowledge management approach to organizational competitive advantage: Evidence from the food sector," European Management Journal, vol. 27, no. 2, pp. 129-141, 2009, doi: 10.1016/j.emj.2008.06.005.

[17] A. Taha Rashid Oqaily, A. Taha Al-oqaily, Z. Bin Hassan, A. Mohammed Rashid, and Z. Amin Al-sulami, "Success Factors of Knowledge Management in Universities (A Case Study: Jordanian Private Universities)," Middle-East Journal of Scientific Research, vol. 22, no. 7, pp. 994-1002, 2014

[18] R. Farooq, "A conceptual model of knowledge sharing," International Journal of Innovation Science, vol. 10, no. 2. Emerald Publishing Limited, pp. 238-260, 2018, doi: 10.1108/IJIS-09-2017-0087.

[19] Z. A. Al-Sulami and H. S. Hashim, "Proposed knowledge management conceptual model to enhance teaching activities throughout web 2.0 technology for academicians," IOP Conference Series: Materials Science and Engineering, vol. 928, no. 3, pp. 0-9, 2020, doi: 10.1088/1757-899X/928/3/032079.

[20] A. L. Harris and A. Rea, "Web 2. 0 and Virtual World Technologies: A Growing Impact on IS Education," Journal of information systems education, vol. 20, no. 2, pp. 137-145, 2009.

[21] A. G. Almekhlafi and E. S. A. Abulibdeh, "K-12 teachers' perceptions of Web 2.0 applications in the United Arab Emirates?," Interactive Technology and Smart Education, vol. 15, no. 3, pp. 238-261, 2018, doi: 10.1108/ITSE-11-2017-0060.

[22] T. A. Abdulkareem and S. M. Eidan, "Online Learning for Higher Education Continuity (during COVID-19 Pandemic)," International Journal of Youth Economy, vol. 4, no. 2, pp. 125-134, 2020.

[23] R. Drazin, "The processes of technological innovation," The Journal of Technology Transfer, vol. 16, no. 1, pp. 45-46, 1991, doi: $10.1007 / \mathrm{bf02371446.}$

[24] H. O. Awa, O. U. Ojiabo, and L. E. Orokor, "Integrated technology-organization-environment (TOE) taxonomies for technology adoption," Journal of Enterprise Information Management, 2017.

[25] R. Matikiti, M. Mpinganjira, and M. Roberts-Lombard, "Application of the technology acceptance model and the technologyorganisation-environment model to examine social media marketing use in the South African tourism industry," South African Journal of Information Management, vol. 20, no. 1, pp. 1-12, 2018.

[26] J. L. L. Chong and K. Olesen, "A technology-organization-environment perspective on eco-effectiveness: a meta-analysis." Australian Computer Society, 2017.

[27] R. Pillai and B. Sivathanu, "Adoption of artificial intelligence (AI) for talent acquisition in IT/ITeS organizations," Benchmarking, vol. 27, no. 9, pp. 2599-2629, 2020, doi: 10.1108/BIJ-04-2020-0186.

[28] N. M. Govender and M. Pretorius, "A critical analysis of information and communications technology adoption: The strategy-aspractice perspective," Acta Commer., vol. 15, no. 1, pp. 1-13, 2015, doi: 10.4102/ac.v15i1.229.

[29] T. Oliveira, M. Thomas, and M. Espadanal, "Assessing the determinants of cloud computing adoption: An analysis of the manufacturing and services sectors," Information \& Management, vol. 51, no. 5, pp. 497-510, 2014, doi: 10.1016/j.im.2014.03.006.

[30] A. M. Zabadi, "Adoption of Information Systems (IS): The Factors that Influencing IS Usage and Its Effect on Employee in Jordan Telecom Sector (JTS): A Conceptual Integrated Model," International Journal of Business and Management, vol. 11, no. 3, p. 25, 2016, doi: 10.5539/ijbm.v11n3p25.

[31] C. J. Collins and K. G. Smith, "Knowledge exchange and combination: The role of human resource practices in the performance of high-technology firms," Academy of management journal, vol. 49, no. 3, pp. 544-560, 2006.

[32] S. Durmusoglu, M. Jacobs, D. Z. Nayir, S. Khilji, and X. Wang, "The quasi-moderating role of organizational culture in the relationship between rewards and knowledge shared and gained," Journal of Knowledge Management, 2014.

[33] B. Y. Obeidat, L. Hashem, I. Alansari, A. Tarhini, and Z. Al-Salti, "The Effect of Knowledge Management Uses on Total Quality Management Practices: A Theoretical Perspective," Journal of Management and Strategy, vol. 7, no. 4, pp. 18-29, 2016, doi: 10.5430/jms.v7n4p18.

[34] S. Alaaraj, Z. A. Mohamed, and U. S. Ahmad Bustamam, "External Growth Strategies and Organizational Performance in Emerging Markets: The Mediating Role of Inter-Organizational Trust," Review of International Business and Strategy, vol. 28, no. 2, pp. 206-222, 2018, doi: 10.1108/RIBS-09-2017-0079.

[35] L. F. Shieh, T. H. Chang, H. P. Fu, S. W. Lin, and Y. Y. Chen, "Analyzing the factors that affect the adoption of mobile services in Taiwan," Technological Forecasting and Social Change, vol. 87, pp. 80-88, 2014, doi: 10.1016/j.techfore.2013.11.004.

[36] A. N. Tashkandi and I. M. Al-Jabri, "Cloud computing adoption by higher education institutions in Saudi Arabia: An exploratory study," Cluster Computing, vol. 18, no. 4, pp. 1527-1537, 2015, doi: 10.1007/s10586-015-0490-4.

[37] M. I. M. Eid and I. M. Al-Jabri, "Social networking, knowledge sharing, and student learning: The case of university students," Computers \& Education, vol. 99, pp. 14-27, 2016, doi: 10.1016/j.compedu.2016.04.007.

[38] N. A. Qader, "The Effect of Entrepreneurial Leader behavior on Organizational Performance An exploratory study in Basra Oil Company," Managerial Studies Journal, vol. 14, no. 28, 2021.

[39] R. V Krejcie and D. W. Morgan, "Determining Sample Size For Research Activities, Educational And Psychological Measurement," Educational and psychological measurement, no. 30, pp. 607-610, 1970.

[40] U. Sekaran and R. Bougie, "Research methods for business: A skill building approach," Long Range Planning, vol. 26, no. 2, p. 136, 1993, doi: 10.1016/0024-6301(93)90168-f.

[41] J. F. Hair, R. E. Anderson, B. J. Babin, and W. C. Black, Multivariate Data Analysis: A global perspective, 7th ed. NJ: Pearson, 2010 


\section{BIOGRAPHIES OF AUTHORS}
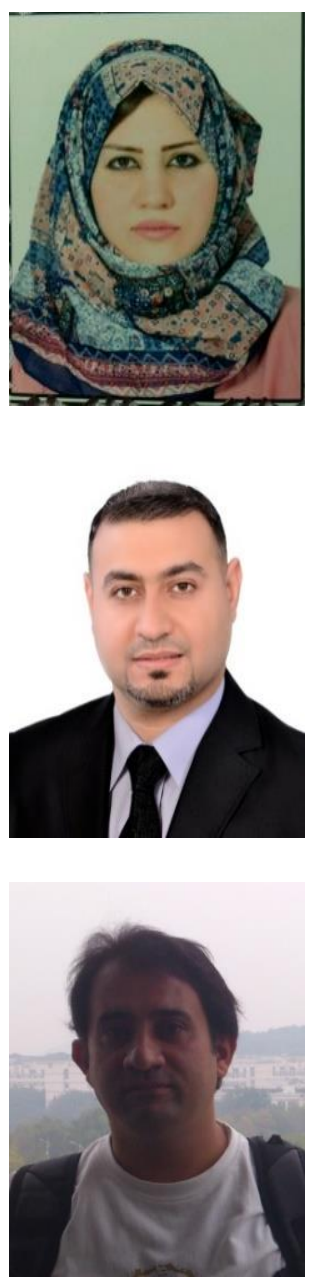

Zainab Amin Abduljabbar (D) SC SC is a lecturer in Basra university. She achieved Bachelor of Computer Science degree from Basra University in Iraq. She achieved Master of Information Technology degree from UNITEN University in Malaysia with special interest in Knowledge Management and cloud computing. In addition, she achieved Malaysian University English Test (MUET) from UNITEN University in Malaysia and she received the best postgraduate student award for her master (vice chancellor award). Currently she is a Ph.D student in Universiti Tenaga Nasional. She can be contacted at email: Zainab.abduljabba@uobasrah.edu.iq

Hayder Salah Hashim (D) 8d SC P is an Associate Professor at the Basrah University, Iraq, where he has been a faculty member since 2010 . Hayder graduated with a degree in computer science from Basrah University, Iraq, in 2009, and an M.Sc. in information and communication technology from Universiti Tenaga Nasional, Malaysia in 2015. He research interests are primarily in the area of knowledge management, cloud computing, internet of things, data mining, and e-learning. Where he is the author/co-author of over 12 research publications. He can be contacted at email: hayder_alasadi@uobasrah.edu.iq.

Zaid Ameen Abduljabbar (D) SC P received the bachelor's and master's degrees in computer science from University of Basrah, Iraq, in 2002 and 2006, respectively, and the $\mathrm{Ph} . \mathrm{D}$. degree in computer engineering from the Department of Computer Science and Technology, Huazhong University of Science and Technology, China, in 2017. His research interests include cloud security, searchable encryption systems, similarity measures, internet of things, secure computation, biometric, and soft computing. He has published regular articles for more than 40 IEEE International Conferences and high-quality articles in SCI journals, and he holds 3 international patents and 2 international computer software copyright. He has always served as a reviewer for several prestigious journals, and has served as the PC Chair/PC member for more than 25 international conferences. He has got the best paper award that published in the 11th International Conference on Green, Pervasive, and Cloud Computing (GPC16), Xian, China, in May 2016. Also, he participated as a visiting scholar programme for international researchers to Huazhong University of Science and Technology and Shenzhen Institute in 2018 and 2019. He can be contacted at email: Zainab.abduljabba@uobasrah.edu.iq. 